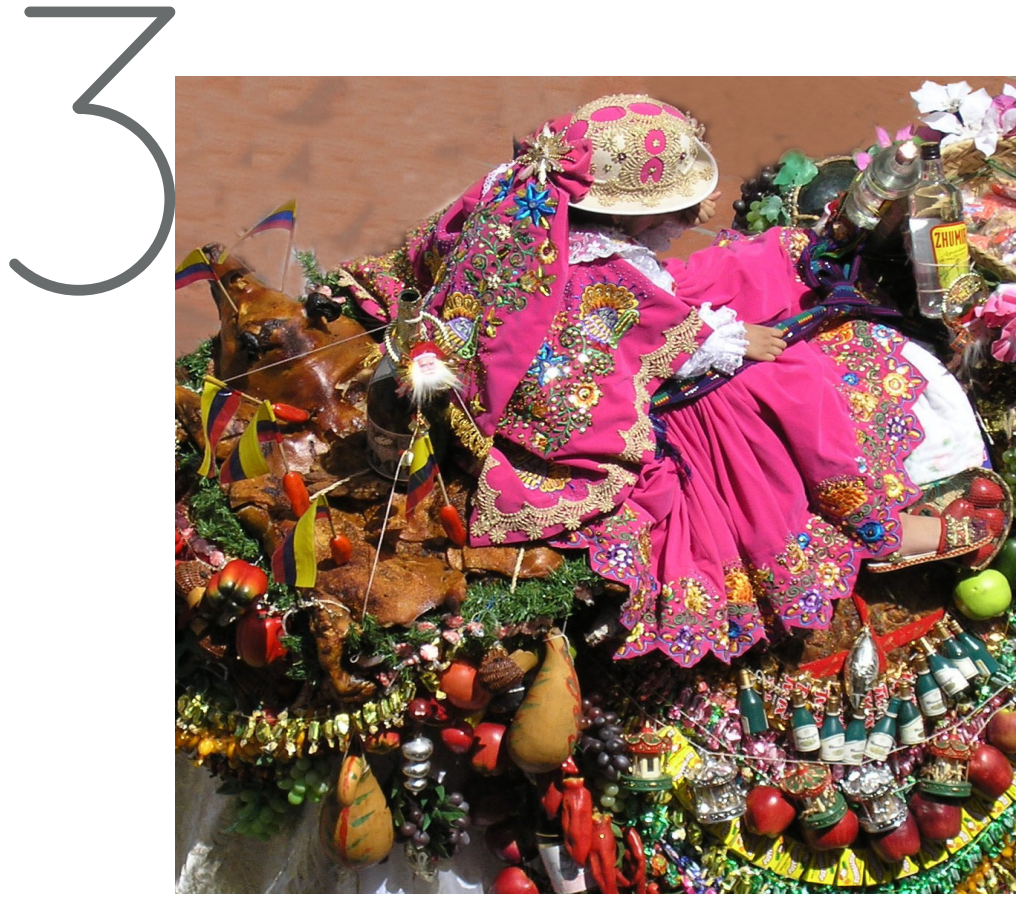

Mayoral en Pase del Niño Cuenca Gabriela Eljuri Jaramillo

\title{
EL PATRIMONIO CULTURAL EN EL NUEVO MILENIO
}

\section{Los patrimonios diversos y el patrimonio como recurso \\ Eljuri Jaramillo, Gabriela ${ }^{1}$}

1 Técnica en Promoción Socio Cultural. Licenciada en Antropología Aplicada. Máster en Estudios de la Cultura con Mención en Patrimonio Cultural. 


\section{Resumen}

En la primera década y media del nuevo milenio presenciamos transformaciones significativas en el abordaje y gestión del patrimonio cultural. Por un lado, en el devenir del debate académico, cambios teóricos, conceptuales y metodológicos han permitido visibilizar patrimonios antes olvidados, aspecto que a su vez, en el plano político, se nutre de profundas reivindicaciones en la lucha por la diversidad cultural y la interculturalidad. En lo referente al rol del Estado, durante los últimos años, el Ecuador ha realizado una apuesta importante por la conservación y salvaguardia del patrimonio.

La conservación y la salvaguardia del patrimonio cultural sustenta su accionar, principalmente, en los valores históricos, simbólicos, identitarios y de continuidad para los pueblos; sin embargo, y sumado a ello, el desafío actual es avanzar y profundizar en una nueva dimensión del patrimonio cultural, en tanto recurso social y económico. Los tiempos actuales plantean nuevos retos para la gestión de la cultura y del patrimonio, y nos obligan a pensar la cultura desde herramientas que no eran propias del ámbito de la cultura y de las ciencias sociales, pero que hoy se vuelven indispensables en el mundo de la economía creativa.

En este contexto, el presente artículo busca dar cuenta de esos cambios conceptuales y metodológicos y dejar planteado, aunque de manera preliminar, la necesidad de un abordaje del patrimonio cultural como recurso para el buen vivir, comprendiendo que los bienes y manifestaciones que integran el patrimonio cultural contienen un gran valor simbólico, en términos de historia, identidad cultural, memoria colectiva y cohesión social, pero también representan un enorme potencial para la generación de conocimiento y nuevas tecnologías, alternativas ambientales y dinamización de las economías locales.

Palabras clave: Patrimonio cultural, patrimonio como recurso, patrimonio y buen vivir, economía creativa. 


\section{THE CULTURAL HERITAGE IN THE NEW MILLENNIUM Heritage diversity and heritage as a resource}

\section{Abstract:}

In the first decade and half of the new millennium we have witnessed significant changes in the approach and management of cultural heritage. On the one hand, the future of academic debate, theoretical, conceptual and methodological changes have helped to expose assets before forgotten, something that in turn, on the political level, is nourished by deep claims in the struggle for cultural diversity and interculturalism. Regarding the role of the state in recent years, Ecuador has made a major commitment to conservation and preservation of heritage.

The conservation and safeguarding of cultural heritage sustains its action mainly on historical, symbolic, identity and the continuity of the people's values; however, and in addition to this, the current challenge is to further apply a new dimension of cultural heritage, in both social and economic resources. The actual times pose new challenges for the management of culture and heritage, and force us to think culture from tools that were not specific to the field of culture and the social sciences, but are indispensable in today's world of creative economy.

In this context, this article seeks to account for these conceptual and methodological changes and leave raised, although preliminary, the need for an approach of cultural heritage as a resource for the well-being, knowing that the assets and manifestations that integrate the Cultural patrimony contain a large symbolic value, in terms of history, cultural identity, collective memory and social cohesion, but also represent enormous potential for generating new knowledge, technology, environmental alternatives and revitalization of local economies.

Keywords: Cultural heritage, heritage as a resource, heritage and good living, well-being, creative economy. 


\section{El patrimonio cultural en los primeros años del nuevo milenio}

A nivel mundial, el abordaje del patrimonio cultural ha cambiado a lo largo de los años. La gestión del patrimonio había estado enmarcada desde connotaciones de monumentalidad, con énfasis en el patrimonio edificado, mientras que el patrimonio vernáculo, los paisajes rurales y el patrimonio cultural inmaterial estaban al margen de los discursos y debates patrimonialistas.

Si miramos los instrumentos internacionales de la UNESCO, y de los cuales el Ecuador es Estado signatario, vemos que la convenciones anteriores al año 2000 versan en su totalidad sobre el patrimonio material, con énfasis en los patrimonios monumentales, edificados y museables, tal es el caso de la Convención para la protección del patrimonio cultural en caso de conflictos armados (1954); la Convención sobre las medidas que deben adoptarse para prohibir e impedir la importación, la exportación y la transferencia de propiedad ilícitas de bienes culturales (1970) y la Convención para la protección del patrimonio mundial cultural y natural (1972).

Es en los primeros años del nuevo milenio cuando se concreta en el seno de la UNESCO la firma de instrumentos que dan cuenta de nuevas miradas sobre la cultura y sobre el patrimonio, miradas que si bien en algunos casos habían sido enunciadas en el pasado, hoy se encuentran respaldadas en el ámbito internacional; así, podemos mencionar la Convención para la protección del patrimonio cultural subacuático, del año 2001; la Convención para la protección y promoción de la diversidad de las expresiones 
culturales, firmada en París el 10 de octubre de 2005; y la Convención para la salvaguardia del patrimonio cultural inmaterial, aprobada el 17 de octubre de 2003. Igualmente, si bien los paisajes culturales ya habían sido contemplados como categoría patrimonial en la Convención de 1972, su definición recién fue operativizada en 1992 y alcanza una delimitación más concreta en la Guía Operativa de 2012.

Por su parte, en Ecuador, al igual que en el resto de América Latina, esa antigua visión, que ponía énfasis en el valor excepcional del patrimonio, se sustentaba en el ideal de homogeneización del Estado-nación y en la búsqueda y producción de una identidad unitaria. Es, precisamente, con el reconocimiento de la diversidad cultural, la legitimación de la plurinacionalidad y la afirmación de los derechos culturales en un país diverso, que existe cabida para el reconocimiento de nuevos patrimonios y abordajes más contemporáneos, aspectos que se ven plasmados en la actual Constitución y en una renovada institucionalidad en el ámbito del patrimonio cultural.

En esta primera década del siglo XXI, Ecuador ha asumido importantes compromisos frente a la cultura y el patrimonio cultural, en el año 2007 se Declaró al Desarrollo Cultural del País como política de Estado, unido a la creación del Ex Ministerio Coordinador de Patrimonio y el Ministerio de Cultura (hoy Ministerio de Cultura y Patrimonio); poco después, entre los años 2008 y 2009 se ejecutó el Decreto de Emergencia del Patrimonio Cultural de la Nación, política que marcó una nueva etapa en la gestión del patrimonio, no solo por la importancia de las obras ejecutadas, sino también porque permitió situar al patrimonio cultural en la mesas de discusión de todos los rincones del país. En el plano jurídico, la Constitución 
de la República del año 2008 garantiza la conservación y salvaguardia de los patrimonios diversos. En términos de inversión, antes del 2008, el Instituto Nacional de Patrimonio Cultural únicamente contaba con recursos de gasto corriente, mientras que el antiguo FONSAL centraba su inversión en el Centro Histórico de Quito; desde el 2008, entre el INPC, el Ex Ministerio Coordinador de Patrimonio y el actual Ministerio de Cultura y Patrimonio, se ha alcanzado una inversión inédita en el ámbito nacional, que supera los 120 millones de dólares, sin contar con la inversión en el patrimonio ferroviario.

La conservación y salvaguardia del patrimonio cultural están contemplados en el Plan Nacional del Buen Vivir; al tiempo que los gobiernos municipales han asumido nuevas e importantes competencias de acuerdo al Código Orgánico de Ordenamiento Territorial, Autonomía y Descentralización, lo que obliga a los municipios a considerar el patrimonio en sus planes de ordenamiento territorial.

En el plano local, y centrando la atención en el Azuay, es importante mencionar la actual Ordenanza para la Gestión y Conservación de la Áreas Históricas y Patrimoniales del Cantón Cuenca, del año 2010, la misma que refleja notables cambios en la forma de abordar el patrimonio cultural, y que ha sido considerada por muchos como pionera a nivel nacional, pues contempla a los inmuebles patrimoniales en su contexto, como parte de un conjunto y no como elementos individuales, al tiempo que categoriza las edificaciones y espacios públicos y define el tipo de intervenciones para cada tipo de bien. En la provincia se evidencia, aunque de manera lenta, la consideración del patrimonio cultural inmaterial y la demanda por la inclusión de enfoques inter y transdisciplinarios en los proyectos de 
conservación. Las universidades han ampliado su oferta académica en la formación en patrimonio, especialmente a nivel de cuarto nivel, al tiempo que el patrimonio ha dejado de ser ámbito de acción exclusivo de los arquitectos, restauradores y arqueólogos, para incluir la mirada de la historia, la antropología, la etnobotánica, la economía, etc.

Los proyectos se encaminan, cada vez con mayor fuerza, a la apropiación ciudadana del patrimonio y a la participación de los actores locales en su conservación, como ejemplo podemos citar el caso de la parroquia de Susudel, concretamente con la iniciativa del Proyecto Vlir CPM de la Universidad de Cuenca en la ejecución de dos Campañas de Mantenimiento y Conservación Preventiva, cuyas acciones permitieron conservar alrededor de 50 inmuebles patrimoniales y el cementerio parroquial, a través de un proceso de intercambio de saberes entre la academia, las instituciones del Estado y la propia comunidad; y, en esa misma comunidad, la investigación participativa del patrimonio cultural inmaterial que se realiza con fondos de Proyectos de Investigación Científica, Desarrollo e Innovación Tecnológica de la Universidad del Azuay.

Por otra parte, a nivel mundial las declaratorias de patrimonio cultural han ampliado y diversificado su alcance. En estos años varios paisajes culturales han sido inscritos en la Lista de Patrimonio Mundial, por citar un par de ejemplos, podemos mencionar el Paisaje Cultural de Aranjuez o el Paisaje Cultural de Río de Janeiro. Igualmente, se ha incrementado la Lista Representativa del Patrimonio Cultural Inmaterial de la Humanidad. Hoy el Ecuador cuenta con cinco patrimonios culturales reconocidos como patrimonio mundial, de los cuales el "Centro Histórico de Quito" y el "Centro Histórico de Santa 
Ana de los Ríos de Cuenca" fueron declarados en la segunda mitad del siglo pasado.

En el año 2001, la UNESCO reconoció "El Patrimonio Oral y las Manifestaciones Culturales del pueblo Zápara" (Declaratoria Binacional Ecuador-Perú), considerando que la tradición oral es para el pueblo Zápara la depositaria de valiosos conocimientos sobre su entorno natural y sus plantas medicinales, con una rica terminología de su flora y fauna, y representante, también, de la memoria colectiva de la región. Más tarde, en el 2012 se incluyó en la Lista Representativa del Patrimonio Cultural de la Humanidad al "Tejido Tradicional del Sombrero de Paja Toquilla Ecuatoriano", reconociendo que los conocimientos y prácticas ligadas al tejido del sombrero son transmitidas de generación en generación y proporcionan a las comunidades detentadoras un sentimiento de identidad y de continuidad cultural, sirviendo de referencia de cohesión social entre los diferentes grupos que viven en las regiones costeras y andinas del Ecuador. Recientemente, en junio de 2014, el Comité de Patrimonio Mundial, aprobó la inscripción del "Qhapaq Ñan-Sistema Vial Andino" en la Lista de Patrimonio Mundial, declaratoria que involucra a Argentina, Bolivia, Chile, Colombia, Ecuador y Perú, tras un trabajo que duró más de diez años (solo para el componente ecuatoriano, se revisaron más de 40.000 folios de documentación histórica; se realizaron y sistematizaron alrededor de 800 fichas técnicas, registrando $653 \mathrm{~km}$ de camino, de los cuales $447 \mathrm{~km}$ corresponden al Qhapaq Ñan y 108,87 km fueron considerados para la nominación debido a su estado de conservación; además de 101 sitios asociados, de los cuales 49 constan en el expediente de la nominación; 
22 secciones y 2 subtramos ubicados en las provincias de Carchi, Imbabura, Pichincha, Chimborazo, Cañar, Azuay, Guayas y Loja. La inscripción en la Lista de Patrimonio Mundial, en los seis países, incluye 693.52 kilómetros de camino y 308 sitios arqueológicos, vinculados a 232 comunidades).

A nivel nacional se ha incluido nuevos bienes $y$ manifestaciones como Patrimonio Cultural de la Nación, incluyendo patrimonios industriales, patrimonios inmateriales (13 Declaratorias entre 2001 y 2009) y patrimonios modernos, tal es el caso de las Declaratorias de El Ejido en la ciudad de Cuenca (2010) o la inclusión de bienes arquitectónicos del patrimonio moderno en la Declaratoria de los Barrios de El Salado, Orellana y Área Central de Guayaquil (2011). En el caso de Cuenca, se valoró la importancia de El Ejido en la contemporaneidad, como catálogo de diferentes momentos históricos de Cuenca, con tipologías arquitectónicas que van desde las quintas hasta las villas y las edificaciones de los años 60 y 70 que dieron fama a la arquitectura cuencana (mayoritariamente de corte moderno y neocolonial), junto con una nueva forma de trazo urbano que abandona el damero o cuadrícula del centro histórico y sigue el trazo radial influenciado por la importante presencia del arquitecto uruguayo Gilberto Gato Sobral en la nueva planificación de la ciudad. En Guayaquil, se incluyó bienes de la arquitectura representativa de la modernidad, correspondientes al período comprendido entre 1920 y 1975 y que representan una amalgama de varios estilos que comprende lo neocolonial, el racionalismo, eclecticismo, movimiento moderno y el estilo internacional. 
En ambos casos se evidencia la incomprensión de los patrimonios modernos en su plena dimensión patrimonial y la aún existente asociación entre patrimonio y antigüedad, sumado a los conflictos provenientes de intereses privados y sobre todo inmobiliarios, prueba de ello son las demandas que debió afrontar el Instituto Nacional de Patrimonio Cultural en torno a la Declaratoria de El Ejido; sin embargo, las sentencias, particularmente las emitidas por los jueces Hugo Darquea López y José Serrano González, magistrales en su contenido, dan cuenta de la importancia del patrimonio y la función social de la propiedad (consagrada desde la Constitución de 1945), la misma que debe estar condicionada y regulada en función del bien común.

Con lo anotado hasta aquí se busca evidenciar que el nuevo milenio ha venido acompañado de nuevas maneras de abordar y gestionar el patrimonio cultural, al igual que de nuevos retos. El accionar actual en torno a los patrimonios los visualiza como un recurso para los pueblos, por su importante valor en términos de historia, identidad cultural, memoria colectiva y de cohesión social $y$, al mismo tiempo, contempla su enorme potencial para el desarrollo endógeno, la generación de conocimiento y nuevas tecnologías, la posibilidad que presenta en alternativas ambientales y también su capacidad para dinamizar las economías locales. En este contexto, la conservación y salvaguardia del patrimonio cultural, en la actualidad, procura avanzar en una visión territorial con la participación activa de agentes sociales y comunidades. 


\section{El patrimonio cultural y el buen vivir}

La conservación del patrimonio cultural es un pilar importante del buen vivir, concepto que nutre y guía la Constitución de la República y el Plan Nacional del Buen Vivir. El buen vivir constituye una alternativa a los planteamientos economicistas del crecimiento y del mismo desarrollo. El hedonismo neoclásico (basado en la satisfacción de los deseos) y base de la economía tradicional, no distinguía las necesidades de los deseos $y$, desde una mirada de la supremacía del consumidor, consideraba que las necesidades eran infinitas, puesto que reflejarían todo lo que el consumidor desea. Desde esa perspectiva, el desarrollo tenía que ver con la maximización del consumo y la satisfacción -no tanto de necesidades sino de deseos- a través de bienes y servicios.

Sin embargo, el buen vivir, aunque tiene múltiples dimensiones y es aún un concepto en construcción, como lo manifiesta René Ramírez, propone tomar distancia de esa visión neoclásica, manifestando que los seres humanos, para vivir bien, no requieren únicamente el consumo de bienes y servicios, sino de aspectos fundamentales, conocidos en las doctrinas contemporáneas como bienes relacionales -el amor, la amistad, el arte, la participación de lo público, la interrelación con los otros y con la naturaleza, etc.- (Cfr. 2012).

Según Ramírez, acercándose más a una visión aristotélica, la vida buena se basa "no solo en el "tener" sino sobre todo en el "ser", "estar", "hacer" y "sentir": en el vivir bien, en el vivir a plenitud" (Ibídem: 15). Para el autor, la vida plena está directamente asociada con el tiempo disponible para la contemplación, la emancipación, la co- 
producción y el co-consumo. Es decir, el tiempo disponible para la vida contemplativa, la producción y consumo de bienes relacionales sería un indicador directo de la vida plena. "Así, la unidad de análisis de la economía no sería el dinero sino el propio tiempo" (Ibíd.: 36).

En este sentido, el disfrute del patrimonio, la contemplación, la identidad, la cohesión social y la solidaridad que éste promueve, se enmarcaría en ese disfrute de bienes relacionales a los que refiere la concepción de una vida buena o del buen vivir. Sin lugar a dudas, el poder integrador y de cohesión social del patrimonio apunta a esta nueva forma de concebir el bienestar del ser humano, basada no en el desarrollo individual de cada persona, sino en el individuo social.

\section{El patrimonio como recurso en el plano social y simbólico}

En el plano social y simbólico, el patrimonio cultural es un elemento fundamental de la identidad cultural de nuestros pueblos. Tanto en los patrimonios materiales como inmateriales, los colectivos se reconocen a sí mismos, al tiempo que se diferencian de los otros. La apropiación de los bienes y manifestaciones del patrimonio cultural da sentido de pertenencia, identidad y continuidad.

Pero también el patrimonio cultural contribuye a la cohesión social. En nuestros países, históricamente azotados por crisis de diferente índole, muchas veces el patrimonio consigue sostener a la sociedad en medio de la fragmentación, ejemplo de ello son las celebraciones festivas, las mismas que forman parte del patrimonio 
cultural inmaterial, y que permiten mantener la integración comunitaria y la solidaridad. Incluso en contextos de separación física, consecuencia de la migración, la fiesta continúa integrando a los pueblos, a través de su eficacia simbólica, a tal punto que se convierte en un espacio que permite al migrante mantener los lazos sociales con la tierra y la gente que dejó en la periferia. Similar situación ocurre con las mingas o cambia manos para los procesos de siembra, cosecha o construcción, que convocan a familiares y vecinos en un contexto de solidaridad y reciprocidad.

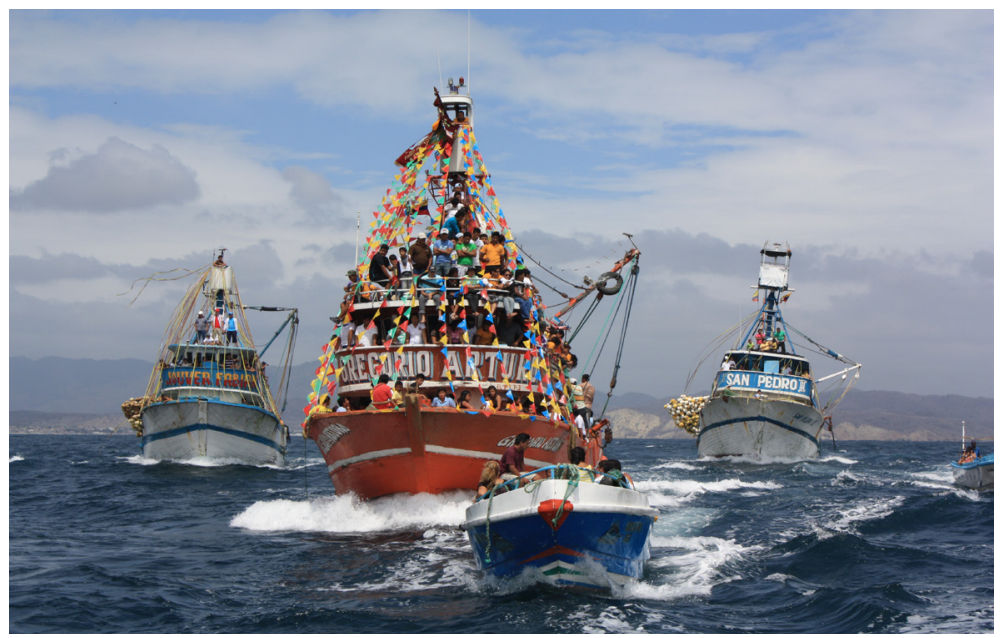

Festival náutico. Gabriela Eljuri Jaramillo

Por otra parte, la conservación y salvaguardia de los patrimonios diversos posibilita el diálogo intercultural, fundamental en la construcción de una nueva democracia, al tiempo que promueve otras formas de conocimiento, no oficiales, que conllevan a una mejor interrelación con los otros y con la naturaleza. 
Herrero Prieto señala que el patrimonio presenta, en términos económicos, externalidades positivas sobre el consumo, puesto que la valoración social del patrimonio produce beneficios externos positivos para las colectividades, cifrados en aspectos fundamentales como el fortalecimientos de la identidad cultural, el desarrollo de la educación y la investigación y la preservación de formas diversas de conocimiento, lo que le convierte al patrimonio en un "bien preferente", llamado por otros "bien meritorio", es decir que, debe proveerse públicamente porque redunda en beneficio del grupo, independientemente de las preferencias individuales (Cfr. 2001: 159).

\section{El patrimonio como recurso en el plano económico}

Pero además del valor del patrimonio vinculado con la identidad, la historia, la cohesión social, la educación y la reivindicación política, el patrimonio también debe ser abordado como un recurso capaz de dinamizar la economía de los pueblos; por tanto, tampoco se debe descuidar la dimensión económica del patrimonio. El patrimonio cultural y la cultura en general, históricamente han permanecido alejados del ámbito de interés de los economistas. Economía y cultura parecían dos ámbitos incompatibles; sin embargo, resulta cada vez más urgente repensar el patrimonio y la cultura, no solo desde sus dimensiones simbólicas, sino también en sus aspectos económicos.

La visión neoclásica del desarrollo centra su atención en el crecimiento económico, por tanto, en esa visión del desarrollo, la cultura y el patrimonio no tienen un lugar importante, menos aún cuando iniciaron los debates sobre 
el "desarrollo" en el contexto de la postguerra, época en la que la cultura era vista como un obstáculo a los objetivos del mismo.

En la actualidad no solo que nuevos patrimonios se han incluido en el debate y en la gestión, sino que también se ha sumado una dimensión adicional al quehacer del patrimonio cultural, en tanto recurso económico. Así, el patrimonio cultural constituye, no solo un recurso simbólico, sino un recurso social con enormes potencialidades para la dinamización de las economías locales. El conocimiento, la conservación y la difusión del patrimonio presentan importantes posibilidades para generar modelos alternativos... no modelos alternativos de desarrollo, sino modelos alternativos al desarrollo.

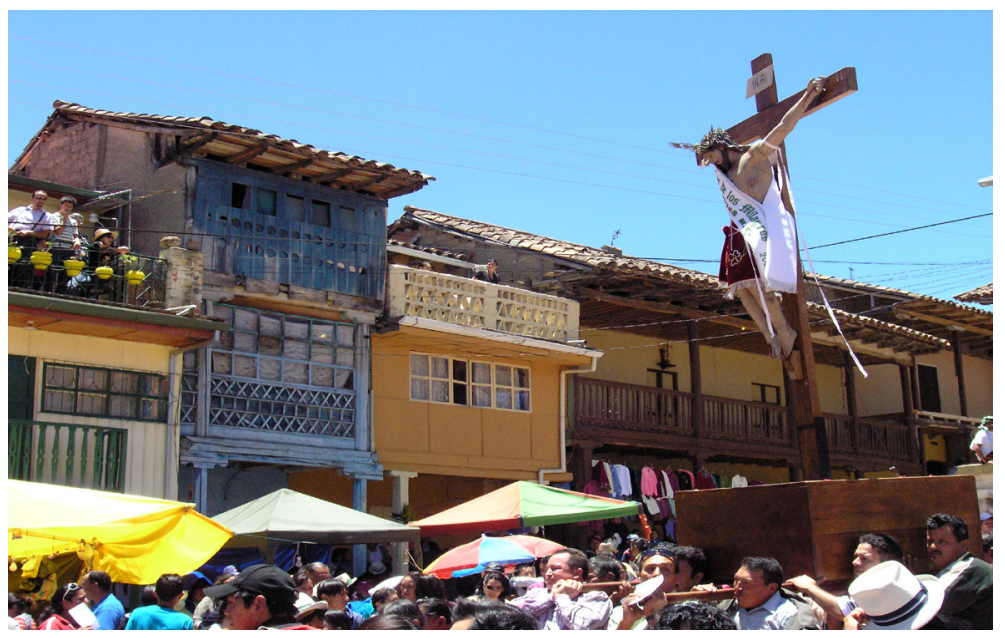

Procesión religiosa. Gabriela Eljuri Jaramillo

Por una parte el patrimonio conservado e investigado puede posibilitar el desarrollo de nuevas tecnologías. 
Por ejemplo, materias primas, técnicas y tecnologías de la arquitectura vernácula pueden contribuir a generar alternativas para la construcción, incluso pueden ser beneficiosas en términos ambientales. En ese sentido es fundamental la investigación para la generación de conocimiento e innovación.

Por otra parte el patrimonio constituye un recurso importante para el turismo cultural, a partir del atractivo que representan los bienes monumentales, los centros históricos, los lugares arqueológicos y, por supuesto, también las manifestaciones del patrimonio cultural inmaterial, sobre todo la gastronomía, las artesanías y las celebraciones festivas. Aquí cabría pensar en cómo, por ejemplo, cuando las ciudades y pueblos apuestan a ingresar a las Listas de Patrimonio Mundial o Patrimonio Nacional, mediante declaratorias oficiales, más allá de los intereses culturales e identitarios, lo que están haciendo -legítimamente- es apostar a figurar en el mapa de los sitios patrimoniales que merecen ser visitados $\mathrm{y}$, por tanto, promovidos turísticamente.

En el mundo entero, el turismo cultural mueve grandes cantidades de gente motivada por enriquecer sus experiencias a partir del conocimiento y contacto con otras culturas. El consumidor de bienes y servicios culturales, invierte en productos cuyo valor no se agota en el momento del consumo sino que se incrementa con el paso del tiempo a partir de la experiencia vivida. Este encuentro entre diferentes, que propicia el turismo cultural, por una parte permite enriquecer el diálogo en la alteridad, pero también dinamizar la economía. En torno a los atractivos turísticos patrimoniales se genera rubros por cobro de entradas a museos y sitios, visitas guiadas, venta 
de artesanías, productos anexos como suvenires, además de la generación de empleo en restaurantes, hospedaje y transporte.

Señala Ernesto Piedras (Cfr. Piedras, 2006) que estos efectos multiplicadores pueden ser vistos como extensiones positivas; por ejemplo, zonas que se ven beneficiadas en la dinamización de sus economías cuando un sitio patrimonial o una manifestación atraen considerables flujos de turistas. Una adecuada gestión de un sitio patrimonial también puede atraer la inversión desde fuera y la generación de emprendimientos productivos desde dentro.

Pero el patrimonio cultural no es solo una fuente de generación de empleos en su puesta en valor y disfrute a través del turismo, sino en el proceso mismo de conservación. Por citar un ejemplo, sabemos que durante el Decreto de Emergencia del Patrimonio Cultural de la Nación, ejecutado entre los años 2008 y 2009, alrededor de 1.000 profesionales y estudiantes de último nivel de carreras afines al patrimonio se involucraron en el Inventario Nacional, más de 5.000 profesionales trabajaron en obras de restauración y colocación de sistemas de seguridad, y se crearon aproximadamente 2.000 empleos indirectos.

Según Eduardo Nivón, en el siglo XX se ha desarrollado una nueva visión del patrimonio como producto que se ofrece en el mercado de bienes simbólicos, al tiempo que, en su conservación y puesta en valor, se presenta una multiplicación de agentes involucrados, entre ellos: medios, empresas, urbanistas, organizaciones civiles, corporaciones turísticas, etcétera. (Cfr. Nivón, op. cit.). 
Piedras encuentra un beneficio adicional, al considerar que gran parte del patrimonio se encuentra en áreas no metropolitanas, por lo que su conservación y puesta en valor podría ser un factor importante para reducir la brecha entre zonas urbanas y rurales (Cfr. Op. Cit.). En ese sentido, vemos cómo contextos rurales empiezan a dinamizarse en torno al patrimonio cultural, a través de sus fiestas, sus artesanías o su arquitectura vernácula. Podemos citar los ejemplos de Sacachún, con el retorno de San Biritute; de El Tambo en Cañar, en donde la mirada territorial ha permitido dinamizar la economía local que antes estaba anclada únicamente al patrimonio arqueológico, o Susudel y Oña en la Provincia del Azuay, cuyos habitantes le han apostado al patrimonio como una herramienta para mejorar las condiciones socioeconómicas locales.

Paralelamente también la conservación del patrimonio cultural permite revitalizar usos degradados y no productivos de los centros históricos. Vemos en la actualidad que en diferentes países del mundo, se procura recuperar los niveles de habitabilidad de los centros históricos. Se busca un adecuado equilibrio entre uso turístico, uso comercial y uso habitacional de los centros históricos, con miras a su vitalidad. Esta apuesta por la sostenibilidad, a su vez, se convierte en una alternativa para el déficit de vivienda que caracteriza a las urbes contemporáneas, puesto que la inversión en rehabilitación de edificaciones patrimoniales ocurre en zonas que ya cuentan con infraestructura existente (agua potable, vialidad, electricidad, alcantarillado, etc.). En tal contexto, la rehabilitación de los centros históricos representaría una ventaja competitiva frente a la generación de nuevas zonas de vivienda, sumado a las ventajas ambientales de la conservación, en relación a la construcción de obra nueva. 
Indudablemente nos encontramos en un nuevo momento para afrontar el patrimonio cultural, su conservación y puesta en valor. Para ello es importante, sin abandonar el objeto que debe estar enmarcado en los valores culturales y simbólicos del patrimonio, pensarlo también como un recurso, para lo cual es importante repensar el patrimonio en términos de economía creativa. Al respecto, las Naciones Unidas, a través de la Conferencia de Comercio y Desarrollo -UNCTAD- y el Programa de Desarrollo -UNPD-, en el año 2008 realizó el Reporte de Economía Creativa, documento que provee de evidencia empírica sobre este sector que al parecer sería el de mayor dinamismo emergente en el comercio mundial.

El documento proporciona importantes datos para el ámbito de las industrias culturales, el patrimonio y la economía creativa en general. Uno de los aspectos que más debería llamar a la reflexión en países como el nuestro, constituye la información referente a las manifestaciones que forman parte del patrimonio cultural inmaterial. Si leemos con atención el Reporte del año 2008, vemos que entre las exportaciones mundiales de todas las industrias creativas, tanto de bienes como de servicios, entre los años 1996 y 2005, las exportaciones en patrimonio pasaron de 15.760 millones de dólares del año 1996 a 26.692 millones en el año 2005, con un índice de crecimiento de 5.4. Del monto correspondiente al año 2005, las artes y artesanías alcanzan los 23.244 millones de dólares (United Nations, 2008).

Según el reporte en mención, "sería irrelevante analizar la economía creativa desde la perspectiva del desarrollo sin prestar atención a las artes y artesanías, las cuales son una de las expresiones 
tradicionales de la creatividad y ciertamente la más importante industria creativa para la mayoría de los países en vías de desarrollo(...) artes y artesanías son la única industria creativa en la que los países en vía de desarrollo tienen una posición de liderazgo en el mercado global (...) A nivel nacional, los esfuerzos para ampliar la producción de artesanías en los países en desarrollo, puede ayudar a preservar la identidad cultural y aportar al desarrollo económico a través del arte y la cultura" (Ibídem: 116).

El Reporte de las Naciones Unidas señala que la transformación de algunos conocimientos tradicionales en bienes y servicios creativos puede tener un potencial económico significativo y cita como ejemplo el Carnaval de Bahía que, en términos cuantitativos, presenta las siguientes cifras (datos del año 2007): 6 días de duración; audiencia estimada de 900.000 personas; 227 grupos; 11.750 artistas involucrados; 131.000 empleos (97.000 del sector privado y 34.000 del sector público); 360.307 turistas nacionales y 96.401 turistas internacionales; 2.531 profesionales de prensa acreditada; $100 \%$ de ocupación hotelera; 94 millones de ingresos generados por turistas; 168 millones de ingresos en facturación; 3.2 millones de ingresos públicos por impuestos; 95 millones de ingresos privados y 27 millones de gasto público (Ibíd.: 39 ).

En elEcuador, si bien no contamos con datos estadísticos actuales referentes a la dinamización económica en torno al patrimonio cultural, un referente que podría llamar a la reflexión es la producción del sombrero de paja toquilla. Esta actividad artesanal permitió el ingreso de las provincias de Azuay y Cañar al mercado exportador mundial a mediados del Siglo XIX, en el año 1854 generó una notable bonanza 
económica en el austro del país, llegando a superar la exportación del cacao y convirtiéndose en aquel año en el producto que mayores ingresos aportó al Ecuador. En el año 1863, desde el Puerto de Guayaquil se exportaron 500.000 sombreros y, por varios años, fue el segundo producto de exportación del país. La actividad toquillera determinó la realidad de las provincias de Manabí, Azuay y Cañar y, en el caso de las dos últimas, las fluctuaciones de las exportaciones determinaron el devenir social, cultural y económico, a tal punto que los primeros flujos migratorios de esas provincias están fuertemente relacionados con esta actividad; igualmente, el desarrollo arquitectónico y cultural de Cuenca se relaciona con los ingresos provenientes de la exportación de sombreros. En los últimos años la exportación de sombreros de paja toquilla fluctúa entre los 8 y 11 millones de dólares anuales, con más de 70 países de destino y un $90 \%$ proveniente de las casas exportadoras de Cuenca. A su vez, la actividad toquillera involucra una compleja trama de actores sociales, entre ellos: cultivadores-productores, cosechadores, secadores y procesadores de la materia prima en la Costa; mayoristas y minoristas cantonales y provinciales de materia prima; pajeras, tejedores y tejedoras de Manabí, Guayas, Cañar y Azuay; perros y comisionistas en la sierra; fábricas exportadoras y reparadores de sombreros para el consumo tradicional interno. Esto sumado a la trama simbólica de elementos identitarios, de distinción étnica, procesos tradicionales de trasmisión del oficio y mecanismos tradicionales de relaciones de intercambio. No podemos olvidar, sin embargo, que detrás de estos datos también se ocultan notables inequidades sociales y económicas.

Si consideramos el ejemplo del sombrero de paja toquilla y cómo su exportación ha permitido sostener la 
economía del Austro, a pesar de su histórico aislamiento, vemos que, en la crisis del capital, que indudablemente afecta más a la periferia que al centro, el patrimonio muchas veces se convierte en el sostén de la economía y de la sociedad.

Con esto queremos ejemplificar, por un lado, la importancia de mirar hacia los patrimonios diversos y, por otro, el potencial del patrimonio cultural para contribuir al cambio de la matriz productiva del Ecuador. Una nueva matriz productiva demanda pasar de un esquema primario exportador a uno que diversifique la producción de manera eficiente, en términos económicos y ambientales, y aproveche los recursos basados en los conocimientos tradicionales de nuestros pueblos, tanto en bienes como en servicios. Creemos que el patrimonio cultural alberga valiosos saberes -técnicas, tecnologías, conocimientos sobre el manejo de los recursos naturales, etc.- para aportar en ese proceso.

Así, "el patrimonio cultural cumple una función múltiple. Es una fuente potencial de ingresos, contribuye a la generación de empleos, creación de empresas, y revitalización y regeneración urbana. Es un instrumento de cohesión social y promueve las libertades culturales" (Cfr. Piedras, 2006).

En tal sentido, el patrimonio cultural presenta un doble valor, alberga un valor simbólico para los pueblos, pero también constituye un recurso económico. El segundo no debería sobreponerse al primero; sin embargo, no mirar al patrimonio como recurso impide la sostenibilidad en su puesta en valor. La conservación y salvaguardia del patrimonio cultural, a fin de cuentas, debe tener una función pragmática para los grupos humanos.

64 
Ahora bien, debe evitarse convertir al patrimonio cultural en una mercancía bajo la lógica del mercado, para ello es importante recordar que nos encontramos ante un recurso particular, en primera instancia no renovable. Esta nueva visión del patrimonio, igualmente, demanda un enfoque territorial en la gestión, procurando involucrar al mayor número de agentes sociales en la conservación de los patrimonios. En este sentido, todo proceso de ordenamiento territorial debe incluir una mirada desde los recursos patrimoniales. "Las nuevas tendencias de la cuestión patrimonial establecen una estrecha relación entre patrimonio y territorio: la gestión del patrimonio ha de ser territorial de la misma forma que la planificación territorial ha de tener en cuenta los recursos patrimoniales" (Martín, 2010: 95).

No proponemos, de ninguna manera, mercantilizar el patrimonio y la cultura; sin embargo, creemos que es importante re dirigir los abordajes de la gestión del patrimonio a una mirada integral que incluya sus posibilidades para el buen vivir. Encontrar un justo equilibrio entre la dimensión simbólico-cultural del patrimonio y su dimensión económica, constituye el reto contemporáneo. Como señala Ana Rosas Mantecón,

"el patrimonio puede ser impulsado y aprovechado en sus posibilidades de generación de empleo y recursos, pero también de enriquecimiento cultural de la ciudadanía por medio de la recreación de identidades, incorporación de valores culturales contemporáneos y fortalecimiento de canales de participación social" (Mantecón, 2010: 177).

Los impactos del aprovechamiento irresponsable de los recursos culturales y de la mercantilización de la 
cultura indudablemente pueden ser nocivos, por ello la importancia de una adecuada gestión y políticas integrales para el óptimo aprovechamiento de los recursos, en el marco de un equilibrio sano entre el valor simbólico del patrimonio y el patrimonio como recurso económico. Urge, al mismo tiempo, profundizar la investigación económica del sector, con la generación de indicadores cuantitativos y estadísticos que permitan no solo identificar su contribución en términos económicos, sino también sustentar con mayores elementos la importancia de su conservación.

El camino por recorrer es aún largo, el debate en el ámbito teórico -ventajosamente- no se ha agotado, tampoco las posibilidades de gestión. 


\section{Bibliografía:}

Asamblea Constituyente, Constitución de la República del Ecuador, Montecristi, 2008.

Herrero Prieto, Luis César, Economía del patrimonio histórico, en Economía de la Cultura, número 792, España, ICE, junio-julio de 2001.

Mantecón, Ana Rosas, El giro hacia el turismo cultural: participación comunitaria y desarrollo sustentable en: Gestionar el patrimonio en tiempos de globalización. México, Universidad Autónoma Metropolitana, Unidad Iztapalapa / Juan Pablo Editor, 2010.

Martín, Marcelo, Patrimonio y sociedad: recursos, interpretación y desarrollo local en: Gestionar el patrimonio en tiempos de globalización. México, Universidad Autónoma Metropolitana, Unidad Iztapalapa / Juan Pablo Editor, 2010.

Nivón, Eduardo, Del patrimonio como producto. La interpretación del patrimonio como espacio de intervención social en: Gestionar el patrimonio en tiempos de globalización. México, Universidad Autónoma Metropolitana, Unidad Iztapalapa / Juan Pablo Editor, 2010.

Piedras, Ernesto, Industrias y patrimonio cultural en el desarrollo económico de México, en: Cuicuilco. Revista de la Escuela Nacional de Antropología e Historia. Nueva Época, Volumen 13, Número 38, México D.F., Instituto Nacional de Antropología e Historia, Septiembre-Diciembre, 2006.

Ramírez, René, La vida (buena) como riqueza de los pueblos. Hacia una sociología política del tiempo, Quito, IAEN, INEC, 2012.

UNITED NATIONS. "Creative Economy Report 2008. The challenge of Assessing the Creative Economy: towards Informed Policy-making", Switzerland, UNPD, UNCTAD, 2008. 
